Journal of Social Sciences 5 (4): 362-369, 2009

ISSN 1549-3652

(C) 2009 Science Publications

\title{
Analysis of Students with Psychiatric Disabilities in Higher Education
}

${ }^{1}$ Azizi Yahaya, ${ }^{1}$ Jamaludin Ramli, ${ }^{1}$ Shahrin Hashim, ${ }^{2}$ Mohd. Ali Ibrahim and ${ }^{3}$ Zurih 2 Lakaria

${ }^{1}$ Department of Foundation Education, Faculty of Education, Universiti Teknologi Malaysia, 81310 UTM Skudai Johor Malays

${ }^{2}$ Department of Mathematics and Science, Faculty of Educa University Technology Malaysia, 81310 UTM Skudai Johor

${ }^{3}$ Ministry of Youth and Sport, Putrajaya

Abstract: Problem statement: With the advent of improved psychiatr nedica phenomenal increase of students with psychiatric disabilities studving at higher e. on in North America. Similarly in Malaysia and unaware to many, there growing nut of such a population. The aim of this research was to determine the with psychiatric disabilities studying at higher education i four related variables (coping difficulties, symptomatology The survey was conducted at Sultanah Aminah Hospital study was done in Sarawak General Hospital, Kuching.) ographic characteristics of students hore and their /vel of performance at (f-esteem ano demic achievement). Permai Hos ach: D respondents was collected using a questionp and analyzu , Johore. (The pilot rom a sample of 30 Social Sciences (SPSS) v.13. Results: B tang descripun statics on demographic characteristics, their level of coping difficultie self-esteem high and academic achievement at a GP $\quad 03$ (out of a 4 point system). The findings imply coping difficulties experienced, the ot powe a danger, the role change to being a "student" assisted recovery an lings als the capability to pursue educational goals. Conclusion: Recommendation te made to fessionals and co-workers, as well as policy makers (the latter regarding roposed rans with abilities Act 2002).

Key words: Psychiat*ic dis coping difficulties, illness symptoms, self-esteem

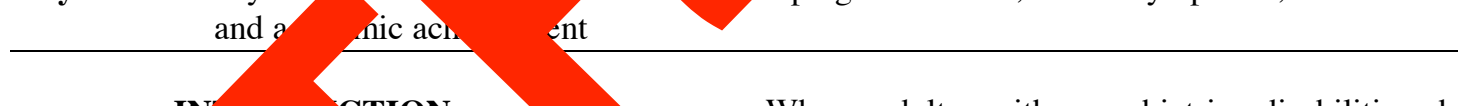

Adults wit have been in as mostly too ill, unmotivated uptive, acaden unprepared and incapable meeting the do ds of higher educat How there have been reports of a proli n of ats with psychiatric disabilities in higher settings forth America ${ }^{[2]}$. Within

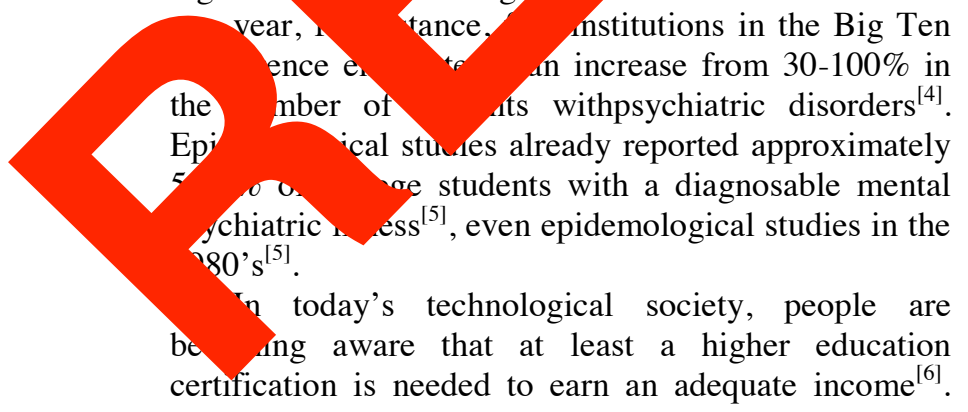

When adults with psychiatric disabilities become students at higher education, it has been found that the role change to a "student" status instead of the stigmatized and devalued label of a "patient" aided recovery ${ }^{[7]}$.

Aim of study: In Malaysia, likewise and unknown to many, there has been a growing number of students with psychiatric disabilities studying in higher education. The aim of this research was to determine the demographic characteristics and performances in four related variables among students with psychiatric disabilities at higher education in the state of Johore. The objectives were:

- To determine their demographic characteristics (such as gender, age, race, diagnosis, years since diagnosis, educational program, educational institution, registration mode and student type)

Corresponding Author: Azizi Yahaya, Department of Foundation Education, Faculty of Education, University Technology Malaysia, 81310 UTM, Skudai Johor, Malaysia Tel: +60127570298 Fax: +607550542 
- To determine their levels of coping difficulties experienced and current symptomatology, selfesteem and academic achievement

\section{MATERIALS AND METHODS}

The research carried out was a survey. The following describes the sample and sampling method, the instrument used and the procedure of the survey.

Sample: The sample of the research was made up of 30 respondents. The respondents were obtained from Sultanah Aminah Hospital and Permai Hospital, which are the two major government hospitals with psychiatric facilities in Johor.

As the two hospitals had not completely computerized their database of patients, the total population of students with psychiatric disabilities studying at higher education could not be ascertained. Therefore, a purposive sampling method was employed. The first 30 respondents who met the following four criteria were selected:

- Currently studying in higher education and $\mathrm{n}$ taking an illness break (higher education refers to certificate, diploma, graduate diploma, bachelor degree, postgraduate degree ternal professional certification)

- Registered as outpatients

- Diagnosed by the psychi with one or more of fo disorders:

- Mood disorde

- Anxiety di

- Psychotic

$$
\text { order }
$$

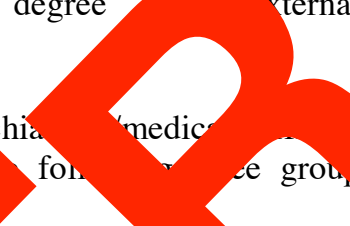

- Illness $m$ not be a tra schizo iform, brief ps) disorder and pos matic ess disorder)

Instr a $T$ astrumen was a structured survey question was ma several sub-scales.

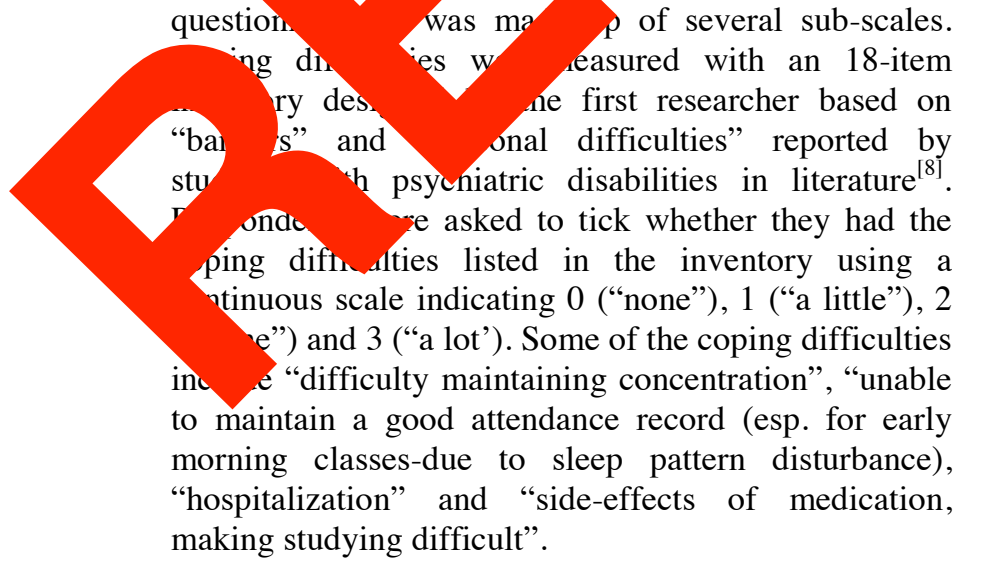

The symptomatology of all the three disorders (mood, anxiety and psychotic) was with an established scale, the Modified C Symptom Index ${ }^{[9]}$. The Modified Color Index (MCSI) has 14 items and its ranged from a value of 0 (none every day). The MCSI measures illness symptoms of the last one survey.

Self-esteem was me item Rosenberg Sel health psychology ("strongly disagree to 4 ("s vagree").

The respondents' academi vement measured was in th their latest Point Average (GPA) GPA adopted as the stanard for the study was a ding to the ding system of University Techn y Malaysia TM), Skudai. Where the respon academic alt was in the form of a grade, onversio $\delta$ a GPA-equivalent was documente $y$ purpose $^{[9]}$. Where it was in arm of a peruenlage, it was converted to a GPAa using a mathematical formula created by the first and checked by referring to a duato Statistics lecturer. A photocopy of the ondents' academic result was requested as a umentary evidence.

Pocedure: Prospective respondents were selected using a manual search through the files guided by the Random Number Table ${ }^{[10]}$ as the terminal digit system of the government hospitals had all the patient files organized into 100 divisions. Recommendations of patients were also provided by psychiatrists and some patients were called on when they came to the hospitals for their regular psychiatric consultations. Then they were further screened through to ensure they met the sample criteria, before invitation to participate was given. The questionnaire was either self-administered at respective hospitals or sent as a postal questionnaire (to those studying/residing in the hinterlands of Johor, other parts of Malaysia and overseas). An informed consent form ${ }^{[1]}$ briefly describing the research and confidentiality assured was given and signed by the respondent. The 30 respondents that made up the sample comprises of 21 from Sultanah Aminah Hospital and 9 from Permai Hospital.

A pilot study conducted earlier was at Sarawak General Hospital, Kuching; with 10 respondents. Feedback from the pilot study provided information for improving the instrument and the reliability tests found the Cronbach's alpha for all the above-mentioned scales ranging from $0.859-0.962$. 
Data analysis: The analytical techniques used with the Statistical Package for Social Sciences (SPSS) version 13 were mean, standard deviation, frequency and percentage. The interpretative scales for the variables reported under Objective 2 were divided into five divisions, ranging from "very low level" to "very high level".

Findings: There were no missing value as the first researcher called the respondents to complete items missed out in the questionnaire, so $\mathrm{n}=30$ for all variables and demographic characteristics examined. The findings below are reported according to the objective they come under.

Objective 1: The 30 respondents were made up of slightly more males $(\mathrm{n}=16,53 \%)$ compared to females $(\mathrm{n}=14,47 \%)$.

Table 1 shows the distribution of the sample respondents' gender. The 30 respondents were made up of slightly more males $(\mathrm{n}=16,53 \%)$ compared to females $(\mathrm{n}=14,47 \%)$.

Table 2 shows the distribution of the responden age. The youngest respondent was 18 years old whi the oldest was 58 years old. The mean age is 25.03 . The variance is wide, with a standard deviation 7.6 . The most common age is 26 with 6 respon age range which is most common with half the sample $(53 \%, \mathrm{n}=1$ The second most common age rà of the respondents $(n=7)$. the respondents $(90 \%$ and 30 .

As seen in $\mathrm{Ta}$ Malays $(\mathrm{n}=19$,
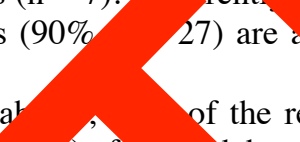
ang in tb ng in th The old,

Table 4 shows the diagnosis of the responde terms of specific disorder, the most comm schizophrenia $(23 \%, \mathrm{n}=7)$ and what was diagnosed as "depression" ( $23 \%, \mathrm{n}=7)$ was an unspecific diagnosis written which could be any of the depres That is, major depressive diso dysthymia or depression with $\mathrm{p}$ depressive disorder and bi most common specific the respondents ead' disorde listed: disorder, dysthym with psycho eature and schizoaffecti disor $\%, \mathrm{n}=2$ each). Apparently, there was no geno anxiety disorder reported.

In 5 , most of the respon, nts selected had only i cent years be diagnosed. The minimum durati ince diagnos respondents was 0.5 year while naximum $\mathrm{w} \quad 0$ years. The mean years since ondent was 3.11 years $(\mathrm{SD}=2.05$, de were 3.0 and 4.0 years and median 3.0 years. Apparently, the years since a. $\mathrm{f}$ most of the respondents clustered around the ft

Tabı 6, slightly over half of the respondents $6, \mathrm{n}=17$ ) were studying in a bachelor degree ram, either locally or overseas. This is followed by ma or advanced diploma programs with $23 \%$ of Table 3: Frequency and percentage distribution on respondents' race

\begin{tabular}{lcc} 
& Frequency & Percentage \\
\hline Malay & 19 & 63.3 \\
Chinese & 9 & 30.0 \\
Indian & 2 & 6.7 \\
Others & 0 & 0.0 \\
\hline Total & 30 & 100.0 \\
\hline
\end{tabular}

Table 4: Frequency and percentage distribution on respondents' diagnosis

\begin{tabular}{lcc}
\hline & Frequency & Percentage \\
\hline Mood disorder & & \\
Major depressive disorder & 3 & 10.0 \\
Bipolar disorder & 3 & 10.0 \\
Dysthymia & 2 & 6.7 \\
Depression with psychotic feature & 2 & 6.7 \\
"depression" & 7 & 23.3 \\
Sub-total & 17 & 56.7 \\
Anxiety disorders & & \\
Panic disorder & 2 & 6.7 \\
Obsessive compulsive disorder & 1 & 3.3 \\
Mixed anxiety depression & 1 & 3.3 \\
Sub-total & 4 & 13.3 \\
Psychotic disorders & & \\
Schizophrenia & 7 & 23.3 \\
Schizoaffective & 2 & 6.7 \\
Sub-total & 9 & 30.0 \\
\hline Grand total & 30 & 100.0 \\
\hline
\end{tabular}


Table 5: Frequency and percentage distribution on years since diagnosis of respondents

\begin{tabular}{lll}
\hline Years since diagnosis & Frequency & Percentage \\
\hline 0.5 & 3 & 10 \\
1.0 & 3 & 10 \\
2.0 & 6 & 20 \\
3.0 & 7 & 23 \\
4.0 & 7 & 23 \\
5.0 & 1 & 3 \\
6.0 & 1 & 3 \\
7.0 & 1 & 3 \\
10.0 & 1 & 3 \\
\hline Total & 30 & 100 \\
\hline
\end{tabular}

Mean $=3.11, \mathrm{SD}=2.05$, Range $=9.5(\min =0.5, \max =10)$

Table 6: Frequency and percentage distribution on respondents' educational program

\begin{tabular}{lcc}
\hline & Frequency & Percentage \\
\hline Certificate & 2 & 6.7 \\
Diploma or advanced diploma & 7 & 23.3 \\
Bachelor degree & 17 & 56.7 \\
Graduate diploma & 1 & 3.3 \\
External professional & 1 & 3.3 \\
Postgraduate degree & 2 & 6.7 \\
\hline Total & 30 & 100.0 \\
\hline
\end{tabular}

Table 7: Frequency and percentage distribution on responden educational institution

\begin{tabular}{lcc}
\hline & Frequency & Percentage \\
\hline Non-UTM students & 21 \\
UTM students & 9 \\
\hline Total & 30
\end{tabular}

Total

Table 8: Frequency and percentage registration mode

Full-time students

Part-time students

Total

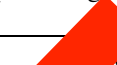

dis op
aency

the respond $\quad(n=7)$. There students $(7 \%)$ each stud in a certificate and oraduate degree progra nly on ydent was studying a graduate diplo ther in an external professional certific.

Table ( $3 \%$ ea rove $\mathrm{s}^{\mathrm{l}}$ the distribution of the dents institution. Item 9 in the den aphy sea the questionnaire was an openend ron, ası, for the respondents' educational ir location. Deriving from Item 9, it was and that $(\mathrm{n}=9)$ of the respondents were from TM, Skudai. Most of the other $70 \%$ were from higher ation institutions both in Johor and in other parts of Malaysia (none apparently studying in East Malaysia). Two respondents were studying overseas: one in Singapore and the other in Taiwan. The respondents other than those studying in UTM, Skudai were categorized under "Non-UTM students".
Table 9: Frequency and percentage distribution on student-typ

Type I students (ill during study program) Type II students (ill before study program) 15 Total

From Table $8,93 \%$ of the were full-time students while $7 \%$ students.

Table 9 above respondents are. This objective of this sty the respondents b elation to the current educational pursuit.rt was to hat an equal number of them $(\mathrm{n}=\mathrm{n} \%$ ) were Typ dents (those who became $i$ aeir current edu pursuit) and Type $I$ dents (those who became ill before their curren acational purs

Descri analysis: is section on descriptive analysis riptive statistics of all the study varı. difficulties, elements of arted Educauon, current performances (academic oms) and support for Supported
illne the valid number of responses for all oms) and support for Supported
illne the valid number of responses for all ables is, again, 30 as there is no missing value in all questionnaire responses.

Onjective (ii):

Level of coping difficulties: Objective (ii) is to determine the level of coping difficulties among the mentally unwell students.

The coping difficulties inventory has a 3-point scale ranging from $0-3$ (scale shown toward the top of Table 10 in the following page). The overall mean of coping difficulties is $0.99(\mathrm{SD}=0.62)$. One respondent reported no coping difficulties at all. Based on the interpretative scale for coping difficulties, the level of coping difficulties experienced by the respondents is therefore "low".

Table 10 below shows the descriptive data of every questionnaire item measuring coping difficulties. The coping difficulty experienced the greatest by the sample is the difficulty maintaining concentration, with a mean of $1.67(\mathrm{SD}=1.06)$. Thirteen percent of the respondents had no difficulty maintaining concentration, 37\% had "a little", 20\% "some" and 30\% "a lot". The difficulty maintaining concentration is mostly at "a little" level or "a lot".

The second greatest coping difficulty is test or nontest anxiety (mean $=1.60, \mathrm{SD}=1.00)$. Thirteen percent of the respondents reported no test/non-test anxiety, while most of the responses (37\%) experienced "a little" of it, 27\% "some" and 23\% "a lot". 
Table 10: Descriptive data on questionnaire items of coping difficulties

\begin{tabular}{|c|c|}
\hline 1 & Difficulty maintaining concentration \\
\hline 2 & Problem with memory \\
\hline 3 & Difficulty meeting deadlines \\
\hline 4 & Unable to handle group discussions \\
\hline 5 & $\begin{array}{l}\text { Unable to maintain good attendance record (due to sleep } \\
\text { pattern disturbance) }\end{array}$ \\
\hline 6 & $\begin{array}{l}\text { Lack of meta-cognitive skills (e.g., planning, organizing, } \\
\text { making decisions) }\end{array}$ \\
\hline 7 & $\begin{array}{l}\text { Lack of study skills (e.g., notes-taking, mind-mapping, exam } \\
\text { techniques) }\end{array}$ \\
\hline 8 & $\begin{array}{l}\text { Lack of academic ability (e.g., inability to handle course load, } \\
\text { failing exams) }\end{array}$ \\
\hline 9 & Test anxiety or non-test anxiety \\
\hline 10 & $\begin{array}{l}\text { Other illness symptoms (e.g., mood swings, depression, delusions, } \\
\text { overwhelmed/stressed out) }\end{array}$ \\
\hline 11 & Hospitalization \\
\hline 12 & Substance-abuse, disruptive/inappropriate behavior or legal issues \\
\hline 13 & Side-effects of medication \\
\hline 14 & $\begin{array}{l}\text { Dealing with mental illness stigma (e.g., fear of disclosure } \\
\text { or discrimination) }\end{array}$ \\
\hline 15 & Conflicted relationships with family member(s), peers or faculty \\
\hline 16 & $\begin{array}{l}\text { Mental health professional, faculty or family member(s) y } \\
\text { of academic pursuit }\end{array}$ \\
\hline
\end{tabular}

17 Competing circumstances (e.g., competing family obligat finding time to study while holding a job)

18 Physical health problem (e.g., frequent flu, epilepsy, fatigue lack of stamina)

Overall mean $=0.99, \mathrm{SD}=0.62,(\mathrm{n}=30)$

They had other illness sy swings, irritable moods, host motivation, depression, dely ions, overwhelmed/stressed out third greatest coping $(\mathrm{SD}=1.07)$, with 1 $33 \%$ at "a little" le

The fourth iculty. Th $n$ is 1.60 serio ving difficulty is a problem with nory. The mu $1.30(\mathrm{SD}=1.15)$. Although of the responses reported not experie it; $2^{2}$ "reported it a "a little" level, anoth \% "sor and $20 \%$ "a lot".

i. $k$ eta-cogr ive skills (e.g., planning, organiziı aking d ns) was also experienced

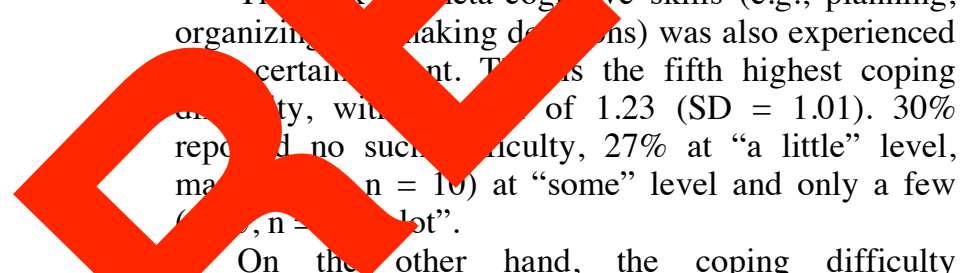

On thw other hand, the coping difficulty verienced the least is substance-abuse,

tive/inappropriate behavior or legal issues with ci al justice system $($ mean $=0.10, \mathrm{SD}=0.40)$. Almost all the respondents $(93 \%, \mathrm{n}=28)$ reported no such problem while pursuing their current educational program. 3\% $(\mathrm{n}=1)$ reported "a little" and also at "some" level.
Distribution of responses (\%)

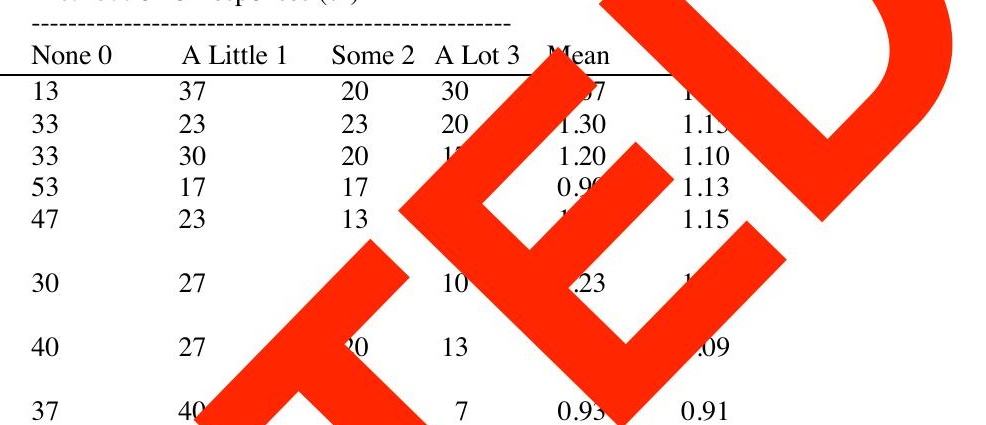

37
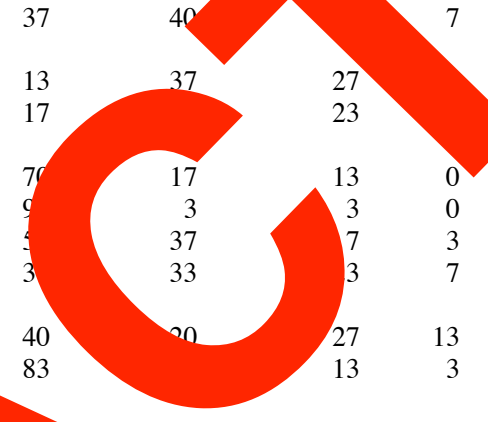

$0.93 \bigcirc 0.91$

$1.60 \quad 1.00$

$1.60 \quad 1.07$

$0.43 \quad 0.79$

$0.10 \quad 0.40$

$0.60 \quad 0.77$

$1.00 \quad 0.95$

$1.13 \quad 1.11$

$\begin{array}{lll}3 & 0.37 & 0.85\end{array}$

$\begin{array}{lll}17 & 0.93 & 1.11\end{array}$

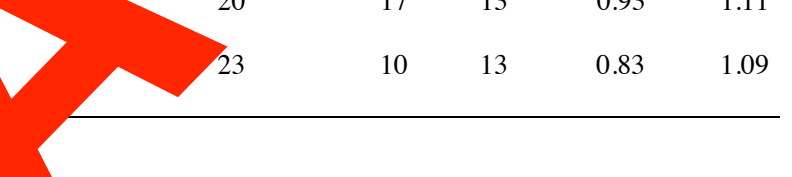

Mental health professional, faculty or family member(s) being unsupportive of academic pursuit is the second least experienced coping difficulty, with a mean of $0.37(\mathrm{SD}=0.85)$. Again, almost the entire sample (85\%) reported no such difficulty. No respondent reported it as experiencing "a little" of this difficulty, $13 \%$ had "some" of this difficulty while only $3 \%(\mathrm{n}=1)$ had "a lot".

Finally, the third least experienced coping difficulty is hospitalization (mean $=0.43, \mathrm{SD}=0.79$ ). $70 \%(\mathrm{n}=21)$ reported not having been hospitalized in the course of their current educational pursuit. Only a total of 9 respondents $(27 \%)$ was hospitalized during the course of their study program; in which $17 \%(\mathrm{n}=5)$ reported it as having "a little" of this problem and 13\% $(\mathrm{n}=4)$ at a "some" level.

\section{DISCUSSION}

The findings in terms of gender are similar ${ }^{[1]]}$ which surveyed a nationwide sample of 522 respondents with the same three group disorders. There has not been any prior study done on students with psychiatric disabilities in Malaysia but a comparison can be made by observing the student population in large higher education institutions in Malaysia. Such 
observation indicates that the findings in terms of age are consistent with the Malaysian higher education student population. Whereas in terms of race, the findings of the current study are consistent with the 2006 racial distribution from the Institute Pengajian Tinggi Swasta (IPTS) or Private Higher Education Institutions and the Malaysian 2004 general population $^{[24]}$. In short, the consistencies with representative data in terms of gender, age and race justifies that the sample is fairly representative of its accessible population (students with psychiatric disabilities in Johor) as well as its target population (students with psychiatric disabilities in Malaysia).

The distribution of diagnoses confirms the findings of some previous research ${ }^{[12]}$. The years since diagnosis confirms again another of Megivern, Pellerito and Mowbray's ${ }^{[13]}$ finding. Working out the "age of first diagnosis" of the sample based on the "year of diagnosis" and "age" reported by the respondents, it was found that $90 \%$ of the sample's age of first diagnosis were between 16 and 28. This is similar vast literature that states that the typical age of onset is around $16-25^{[14]}$. The distribution of $t$ educational program found in the sample showed larger proportion of bachelor degree students and a smaller proportion of diploma and cer udents compared to the 2006 data from the ate ajian Tinggi Awam (IPTAs), or Publ gher E I.ion Institutions. (The data from DTAs representative data of the $\mathrm{I}$ population since students biggest proportion of Malaysia.) The IPT gher educat

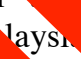
$7 \%$ bachelor ducatio akes up the dents in diploma and 15 erth students. Thu bigger proportion of achelor deg dents and smaller proportion sloma and cen students in the current st an be explained by availability and spread agher ation institutions located in the state Tore almost half of the sample (47\%) were stu n Johor UTM Skudai is a major v mact instity nearly 25,000 students bac $r$ degree $m$. This fact also explains how $30^{\circ}$ ample $(M=9)$ came from the UTM Skudai.

1ic hution of the student types (the Type I a Type lidents) also confirms Megivern, Pellerito d Mowbray's ${ }^{[13]}$ finding.

The low level of coping difficulties and illness sy $\mathrm{ms}$, high level of self-esteem and good academic achievement can be explained by the fact that the sample are students with psychiatric disabilities who are currently studying and not having an onset/relapse or taking an illness break. A finding from an item in the questionnaire found $70 \%$ of the students having maintenance of medication and consultation.

All the individual coping difficult: symptoms specifically listed in ran confirm finding ${ }^{[7,13,14,15,26]}$.

The most prominent cop repeated in illness symptams problem, depression, test trouble making decision

Contrary to the $b$ media on recent $\mathrm{sc}$ with psychiatric disabilities are oenerally not tive, violent or a danger th bund in this besides other literatu port ${ }^{21}$. Only 2 out of we 30 respondents had pr $m$ with the law ubstance abuse or disruptive behav The feeling $t$ rt oneself or to hurt others were s. oms lowest ccurrence and at least $70 \%$ of the sà $\quad n=21)$ not have such a feeling. The 9 respondo. no experienced such violent ing mostly nu experienced it "once during the to natzlaff et et.$^{[21]}$ findings on adults with hiatric disabilities participating in a Supported cation program which assisted them in their ational pursuit. Consistent with Bley et al. ${ }^{[5]}$ and Murphy and Murphy ${ }^{[19]}$, their level of self-esteem is lower than the general normal population as found by ${ }^{[19]}$. Nevertheless, their self-esteem is of a "high" level according to the interpretative scale for selfesteem.

The academic achievement is almost the same as a normed data of bachelor degree students reported by $\mathrm{Ooi}^{[20]}$, except that the percentage of failure is higher in the current study $(7 \%, \mathrm{n}=2)$ compared to $\mathrm{Ooi}^{[20]}$ at $1.5 \%$. The mean GPA score of 3.03 implies good academic capability among higher education students with psychiatric disabilities. This is supported by Unger and Pardee ${ }^{[26]}$ and Unger ${ }^{[25]}$ who found that higher education students with psychiatric disabilities but assisted with a Supported Education program had mean GPAs of 3.14 (with documentary support) and 3.50 (self-reported). Another finding shows that a majority of his participants in a clubhouse (under a Supported Education program) received $\mathrm{B}$ grades or higher ${ }^{[1]}$.

\section{CONCLUSION}

Firstly, an implication of these findings is that higher education students with psychiatric disabilities are intellectually capable (that is, with maintenance of 
medication and when they are not experiencing a relapse/onset).

Secondly, they experience a certain amount of coping difficulties and illness symptoms. A separate finding of this research, which cannot be ignored, found at least $35 \%$ college attrition rate (withdrawals and deferrals).

Thirdly, the high level of self-esteem of those who are able to maintain their education reflects an improved prognosis resulting from a role change to a "student" status rather than the devalued role of a "patient".

The good academic achievement and high level of self-esteem have demonstrated that the beliefs of people with psychiatric disabilities as entirely incapable of educational pursuit are "myths of the bygone era", as supported by Austin ${ }^{[23,17]}$.

Moreover, students with psychiatric disabilities who are medication-compliant are generally not violent or disruptive.

The appearance of students with psychiatr disabilities or the future appearance of more s students in the campus grounds of Malaysia is example of a paradigm shift. The "rising tide" ${ }^{[23]} \mathrm{O}$ higher education students with psychiatric disabilities has been made possible by the $?$ new generation psychiatric medication wi os Si fects and better psychiatric care ${ }^{[4,13,19,22}$ drugs about improved cognitive ak rehabilitation methods ${ }^{[7]}$

Recommendations:
health professionals and be more ser to oping difficures of a growing num of stu with psychiatric disabilities; support them $\quad \mathrm{v}$ fight it while pursuing ational goals.

A s stud as found that students with psych disa es are capable of academic pursuit and a s. wed nea no-thirds of adults with bilitios atio more education ${ }^{[27]}$; health scould play a leadership role uraging who have academic potential to equ elves with a higher education certification. time, mental health professionals can del a sup dive role for such students.

This study is also a proposition to policy makers that with psychiatric disabilities be formally reed and included in the definition of the disabled in Malaysia so that assistance (like in Education) can be made available for them, supporting the proposed Persons with Disabilities Act 2002 ("Disability Laws", un-dated) being looked into at time of writing.
Finally, it is hoped too that these findings le consideration of a rehabilitation program sue Supported Education program (Goh, in-press) prepares adults with psychiatric disabi resume higher education and suppo psychiatric disabilities till the educational goals. Supported empirically effective rehabilitati there are currently over $\Rightarrow$ pr America $^{[16]}$ and a few and Europe (perso Sullivan-Soydan, sy develop mmunication munication
rcher in ported Education for ove 0 years, recommendation is in line with the need for mor ilitation resources in Malays $\mathrm{d}$ by Mubarak adionts wis ucatio $\overbrace{\text { an }}$ no where in $\mathrm{No}$ $\mathrm{Au}$ a (1) 
8. Collins, M.E., C.T. Mowbray and D. Bybee, 1999. Measuring coping strategies in an educational intervention for individuals with psychiatric disabilities. Health Soc. Work, 24: 279-290. http://www.ncbi.nlm.nih.gov/pubmed/10605633

9. Conrad, K.J., J.R. Yagelka, M.D. Matters, A.R. Rich, V. Williams and M. Buchanan, 2001. Reliability and validity of a modified colorado symptom index in a national homeless sample. Mental Health Serv. Res., 3: 141-153. http://www.ncbi.nlm.nih.gov/pubmed/11718206

10. Creswell, J.W., 2002. Educational researchplanning, conducting and evaluating quantitative and qualitative research. New Jersey, USA. Pearson Education, Inc., ISBN: 10: 013112790X, pp: 640.

11. Goh, S.Y., 2007. The Need for Supported Education among Students with Psychiatric Disabilities. Masters Dissertation, University Technology Malaysia, Skudai. http://eprints.utm.my/6554/

12. Kahng, S.K. and C.T. Mowbray, 2005. Wb affects self-esteem of persons with psychia disabilities: The role of causal attributions mental illnesses. Psychiatr. Rehabil.. J., 28: 354-360 DOI: $10.2975 / 28.2005 .354 .360$

13. Megivern, D., S. Pellerito and C. Barriers to higher education fo psychiatric disabilities. Psyy 26: 217-231. DOI: 10.2975

14. Mowbray, C.T., M. Co Supported educatio psychiatric disabil an experimental http://www.q a.co, vleScholar.qs, session id=KgcYK 2 PLn31 VYq. $\quad$ 5SZMX7JcnQ6Z2d 4Q3Q9 rgVXnljgJn!134 ?doc 01273553

15. M ay, C ad D. Megivern, 1999. Higher ion rehabilitation for people with psy disabiliti J. Rehabil., Vol. 65. http: $/$ uestia googleScholar.qst?docId= 02344

16. wbray, Megivern and M.C. Holter, upporto education programming for adults nationa arvey. Psychiatr. Rehabil. J., 27: 159-167. DOI: $10.2975 / 27.2003 .159 .167$

Mowbray, C.T., D. Megivern, J.M. Mandiberg, Strauss and C.H. Stein et al., 2006. Campus mental health services: Recommendations for change. Am. J. Orthopsychiatry, 76: 226-237. http://www.ncbi.nlm.nih.gov/pubmed/16719642
18. Mubarak, A.R., 2005. Social functionin quality of life of people with schizophrer northern region of Malaysia. Aus. e-J. Adv. Health (AeJAMH), http://www.ausienet.com/journal/y _abstract.pdf

19. Murphy, H. and E.K. Murr quality of life using the Wor Quality of Life meas clinical and non-cli role of self-est self-efficacy functioning. J alth, 15: 289 $10.1080 / 0963000$

20. Ooi, Y.P., 2002. Stre d anxiety among engine lents and no, neering students at Masters Dissè on, University Te ology Malaysia pp: 123-137

21. R ff, S., D. Mc ${ }^{r}$ mid, D. Marty and C. Rapp, 2 The Kansas umer as provider program: Mc $g$ the eff of a supported education initià Rehabil. J., 29: 174-182. http://pry. Com/app/home/contribution.asp ferrer=parent\&backto=issue, 4,14;journal,15,29;1 blicationresults, $1: 119989,1$ 22. Abnormal Psychology. 4th Edn., W.W. Norton and Company, Inc., New York. Sharpe, M.N., B.D. Bruininks, B.A. Blacklock, B. Benson and D.M. Johnson, 2004. The emergence of psychiatric disabilities in postsecondary education. National Centre on Secondary Education and Transition Issue Brief. http://www.ncset.org/publications/viewdesc.asp?id $=1688$

24. Central Intelligence Agency, 2007. The World Factbook.

http://www.cia.gov/library/publications/the-worldfactbook/geos/my.html\#People

25. Unger, K.V., 1993. Creating supported education programs utilizing existing community resources. Sychosoc. Rehabil. J., 17: 11-23. http://psycnet.apa.org/?fa=main.doiLanding\&uid= 1994-03644-001

26. Unger, K.V. and R. Pardee, 2002. Outcome measures across program sites for postsecondary supported education programs. Psychiatr. Rehabil. J., 25: 299-303. http://www.ncbi.nlm.nih.gov/pubmed/11860003

27. Zahniser, J.H., 2004. Psychosocial Rehabilitation. In: The Evidence-Based Practice Methods, Models and Tools for Mental Health Professionals, Stout, C.S. and R.A. Hayes (Eds.). John Wiley and Sons, Inc., New Jersey, ISBN: 10: 0471467472, pp: 384 . 